\title{
Structurally nanoengineered antimicrobial peptide polymers: design, synthesis and biomedical applications
}

\author{
Ronisha Ramamurthy ${ }^{1} \cdot$ Chetan H. Mehta $^{1}$ - Usha Y. Nayak ${ }^{1}$ (i)
}

Received: 23 April 2021 / Accepted: 12 July 2021 / Published online: 19 July 2021

(C) The Author(s) 2021

\begin{abstract}
Antimicrobial resistance not only increases the contagiousness of infectious diseases but also a threat for the future as it is one of the health care concern around the globe. Conventional antibiotics are unsuccessful in combating chronic infections caused by multidrug-resistant (MDR) bacteria, therefore it is important to design and develop novel strategies to tackle this problems. Among various novel strategies, Structurally Nanoengineered Antimicrobial Peptide Polymers (SNAPPs) have been introduced in recent years to overcome this global health care issue and they are found to be more efficient in their performance. Many facile methods are adapted to synthesize complex SNAPPs with required dimensions and unique functionalities. Their unique characteristics and remarkable properties have been exploited for their immense applications in various fields including biomedicine, targeting therapies, gene delivery, bioimaging, and many more. This review article deals with its background, design, synthesis, mechanism of action, and wider applications in various fields of SNAPPs.
\end{abstract}

\section{Graphic abstract}

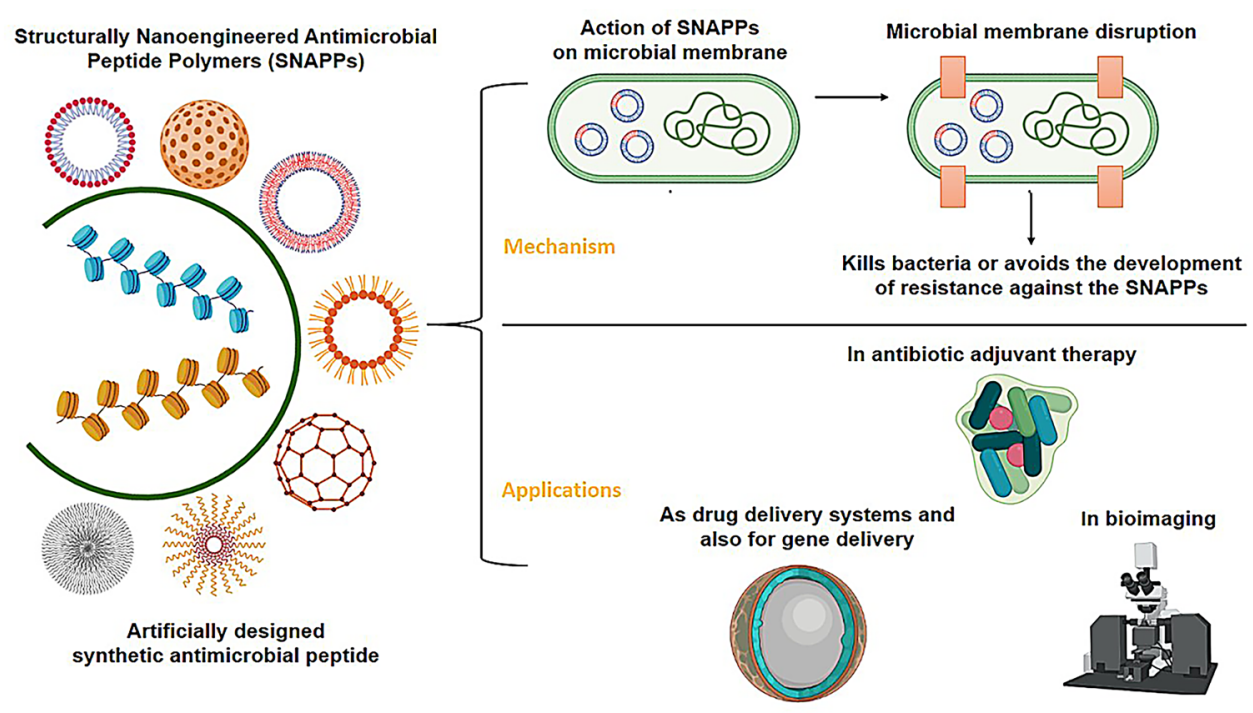

Keywords Antimicrobial resistance $\cdot$ Bio-imaging $\cdot$ Drug delivery $\cdot$ Reversible addition fragmentation chain transfer (RAFT) · Ring-opening polymerization (ROP) · Structurally nano engineered antimicrobial peptide polymers (SNAPPs)

Usha Y. Nayak

usha.nayak@manipal.edu

1 Department of Pharmaceutics, Manipal College

of Pharmaceutical Sciences, Manipal Academy of Higher

Education, 576104 Manipal, Karnataka, India 


\section{Introduction}

Diseases caused by infectious microbes go on to be the greatest challenge and warning to worldwide health care. Although significant progress has been attained over the past few decades with the introduction of novel and effective antimicrobials, current antimicrobial therapy is still experiencing some major setbacks, including lack of selectivity of usual drugs, unwanted side effects, uneconomical and time-consuming synthetic processes, and more importantly the acquirement of multidrug resistance (Brown and Wright 2016; Namivandi-Zangeneh et al. 2019).

The term multidrug-resistant (MDR) bacilli cover specifically the pathogens including Enterococcus faecium, Staphylococcus aureus, Klebsiella pneumoniae, Acinetobacter baumannii, Pseudomonas aeruginosa, and Enterobacter species which are referred to as ESKAPE pathogens and are being considered as critical and high priority organisms to cause unwanted effects. The success rate posed by conventional antibiotics against these organisms has been proved to be only a handful (Boucher et al. 2009; Mahlapuu et al. 2016; Mukhopadhyay et al. 2020). It has been studied from a recent survey that over 700,000 people are getting affected by drug-resistant microbes each year worldwide. The number is estimated to increase to 10 million in another 50 years if no successful steps are taken (Mahlapuu et al. 2016; Shen et al. 2018). Therefore, it is a necessary prerequisite to design, synthesize and introduce novel antimicrobial agents to overcome or tackle the problems associated with antimicrobial resistance (AMR). Figure 1. depicts a continent-wise estimation of the number of deaths by AMR.

The emergence of drug-resistant microbes and the raising concerns about the usage of antibiotics resulted in the development of antimicrobial peptides (AMPs) which are produced as a first line of defense by many multicellular organisms. AMPs are a class of naturally occuring small peptide molecules and have a wide range of inhibitory actions to directly prevent the growth of organisms like bacteria, fungi, parasites, viruses and even cancer cells. AMPs

\section{Estimated no. of deaths at every continent in 2050 atributed to AMR}

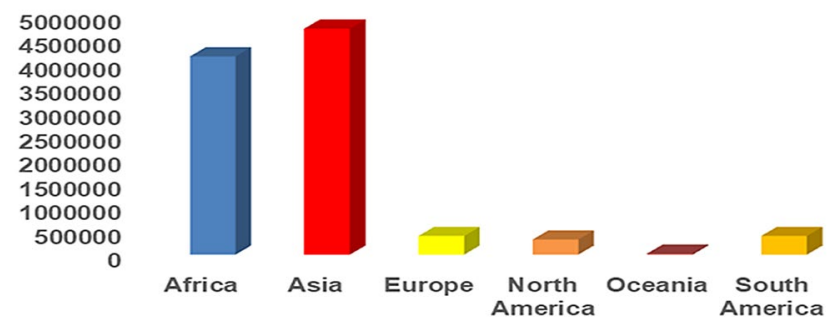

Fig. 1 Continent wise estimation of number of deaths by AMR are classified based on their source, antimicrobial activity, structural characteristics and amino acid composition. Apart from medicine, they also have good application prospects in other fields like food, animal husbandry, agriculture and aquaculture (Mukhopadhyay et al. 2020).

In the past few decades, synthetic replicas of AMPs, a portion of the distinct immune response among all living species have raised focus from researchers as a gifted solution to fight against MDR bacteria (Thomson and Bonomo 2005; Xu et al. 2014; Zu et al. 2014; Gill et al. 2015). These potent, broad spectrum antibiotics are known to exhibit as efficient and novel therapeutic agents which have been proved to be more competitive candidates in antibacterial therapy. There are two types of AMPs based on antimicrobial therapy. The first type refers to inherent antimicrobial polymers which do not involve any modifications while the other type has a need for modifications for the antimicrobial actions. Though having many advantages over common antibiotics, AMPs also faced limited clinical achievements, which may be due to uneconomical manufacturing procedures, inactivation under physiological conditions, a poor profile of pharmacokinetic parameters, and high toxicity in vivo (Ananth et al. 2020; Deslouches et al. 2005; Gill et al. 2015; ). Further, some AMPs exert their actions only under specific experimental conditions and their effect is influenced mainly by forming the interactions between pathogens and tissue-dependent host (Yount et al. 2006; Bechinger and Gorr 2017). These obstructions prevent them from being utilized as efficient systemic therapeutic representatives and many of them are used specifically in topical applications (Rosignoli et al. 2018; Håkansson et al. 2019).

In spite of showing many applications, both natural and synthetic AMPs pose some limitations like damaging the cell membrane of eukaryotes and to cause hemolytic side effects, higher production costs and technical problems, their limited stability at particular $\mathrm{pH}$ and so on. In addition, they show decreased activity in the presence of iron and some serum. Further, they are easily hydrolyzed by proteases.

To triumph over the limitations of AMPs, Structurally Nanoengineered Antimicrobial Peptide Polymers (SNAPPs) have been introduced as novel agents having more potency, stability and bioavailability. SNAPPs indicate a new class of synthetic AMP replicas; exist as star-shaped polypeptide nanoparticles containing hydrophilic lysine and hydrophobic valine amino acid residues (Lam et al. 2016a). These are provided with outstanding antimicrobial characteristics and effective even at very low concentrations against many Gram-negative pathogens including multidrug-resistant bacilli to treat the ailments concerned. They are shown to exhibit minimum toxicity and are proved to display superior selectivity on bactericidal action against numerous Gramnegative pathogens compared to conventional antibiotics and linear AMPs (Ng et al. 2013). 
In recent years, SNAPPs have been given prime importance in various pharmaceutical fields due to their unique properties and also the degree of functionality that has exposed them as potential candidates to act as successful drug delivery vehicles (Torchilin 2007; Peer et al. 2007; Wu et al. 2015; Chen et al. 2015). Attention has also been focussed on their significance for advanced applications in many fields including emulsification, catalysis, gene delivery, bio-imaging, tissue engineering, and many more (Sulistio et al. 2011; Nakayama 2012). Continued interest in the study of SNAPPs proved them as versatile and unique materials having the potential to employ in high-value pharmaceutical applications. In this article, mainly design, synthesis, mechanism of action, and wider applications of SNAPPs in various fields are discussed.

\section{Design and synthesis of SNAPPs}

SNAPPS in the form of star-shaped peptide polymer nanoparticles, have been recently demonstrated as a new class of antimicrobial agents with superior in vitro and in vivo efficacy and they belong to the class of macromolecular covalently bonded branched architectures (Lam et al. 2016). In their structure, several linear arms are radiating from the central core. They differ from one-dimensional linear polymers in having a higher order of architecture with exclusive properties due to compact 3D structures (Isono et al. 2013). At the core of the structure, there is a multi-functional initiator poly (amidoamine) with primary amines. Lysine and/ or valine amino acids are polymerized to the $\mathrm{N}$-terminus of the core to form polymers of varying arm numbers ranging from S16 or S32. There are several types of star structures known, based on composition and sequence, distribution of the arm polymer, the difference in arm species, functional placements, nature, and size of the core structure. There are three prominent approaches available for the synthesis of star shaped SNAPPs which include the core-first, arm-first, and grafting-onto approach. Each of these approaches has merits and demerits of its own.

\section{Core-first spproach}

In this approach, radiating arms are allowed to build from the pre-prepared multifunctional core. The initiating sites on the core must have equal reactivity to obtain polymeric structures with the same arm number and arm length. Further, the rate of the initiation step should be faster than the propagation step. Since there is controlled polymerization, polymers with better control over structure, functionality, and composition can be prepared easily with better yield by involving this approach. The reactions are generally performed under ice-cold conditions to improve the control of polymerization and to avoid side reactions (Vayaboury et al. 2004; Cheng and Deming 2012). But in this approach, sometimes polymers having low arm numbers and a much smaller core domain may be formed which affects both the arm number and core dimension of the resulting star polymer and causes characterization problems. Figure 2. represents the schematic illustration of the synthetic approaches of SNAPPs via the core-first approach.

\section{Arm-first approach}

This approach adopts the formation of SNAPPs by crosslinking linear polymers involving coupling reaction in a congregant fashion. The first step is arm formation in which linear polymers act as terminal initiating sites where short cross-linkable block segments are obtained first. This is followed by linking together these linear polymers using
Fig. 2 Schematic illustration of the synthetic approaches of SNAPPs via ore-first approach

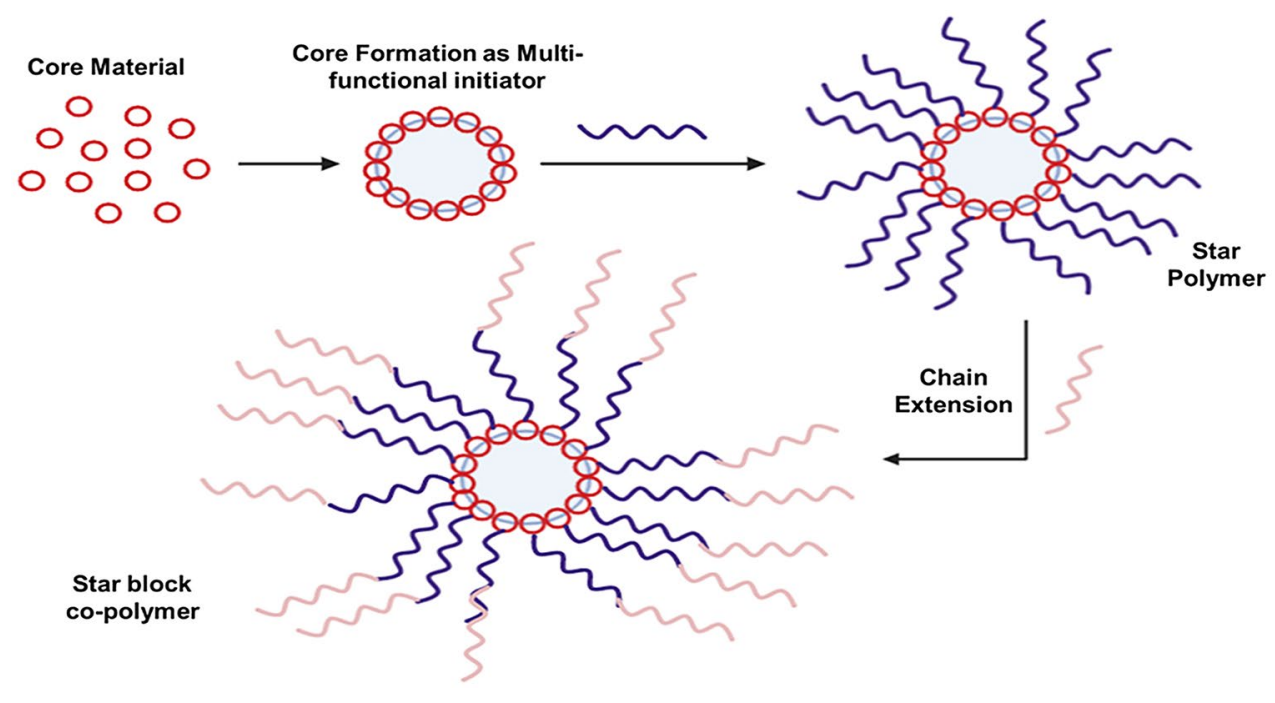


coupling polymerization to yield SNAPPs. This approach offers advantages such as facilitating efficient coupling among cross-linkable functionalities, minimal star-star intermolecular cross-linking, better structural control, and generation of polymers with very high molecular weight and large arm numbers (Bapat et al. 2012). Figure 3 shows the schematic illustration of the synthetic approaches of SNAPPs via the arm first approach.

\section{Grafting-onto approach}

In this approach, synthesis and characterization of core and arm can be done independently before SNAPPs formation. Polymers are obtained by coupling reaction of the multifunctional core and arms which act as a balancing reactive terminus. This is followed by post-polymerization end-group modification. The prepared SNAPPs usually have a low arm number and small core size because of the functionality and dimension of the coupling compounds used and also due to steric factors. Figure 4 gives the schematic illustration of the synthetic approaches of SNAPPs via grafting onto the approach.

\section{Mechanism involved in the SNAPPs formation}

The formation of SNAPPs involves various mechanisms such as ring-opening polymerization (ROP), reversible addition - fragmentation chain transfer (RAFT) polymerization, atom transfer radical polymerization (ATRP) and nitroxide-mediated living radical polymerization (NMP).
Fig. 3 Schematic illustration of the synthetic approaches of SNAPPs via arm first approach

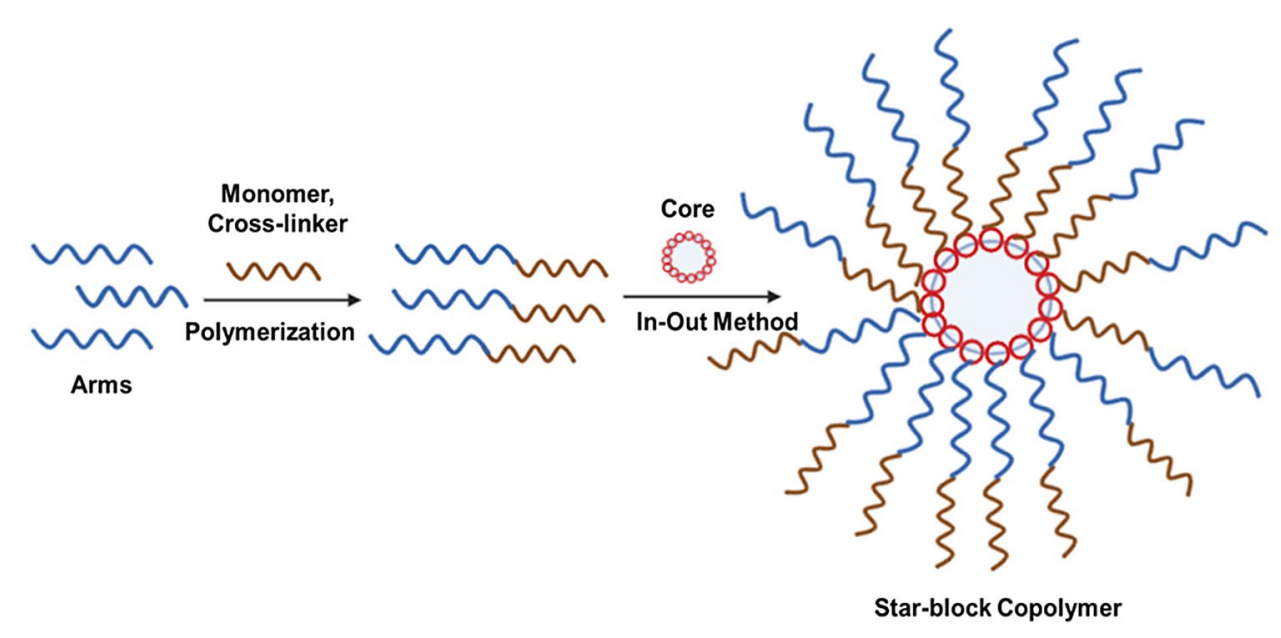

Fig. 4 Schematic illustration of the synthetic approaches of SNAPPs via grafting onto approach

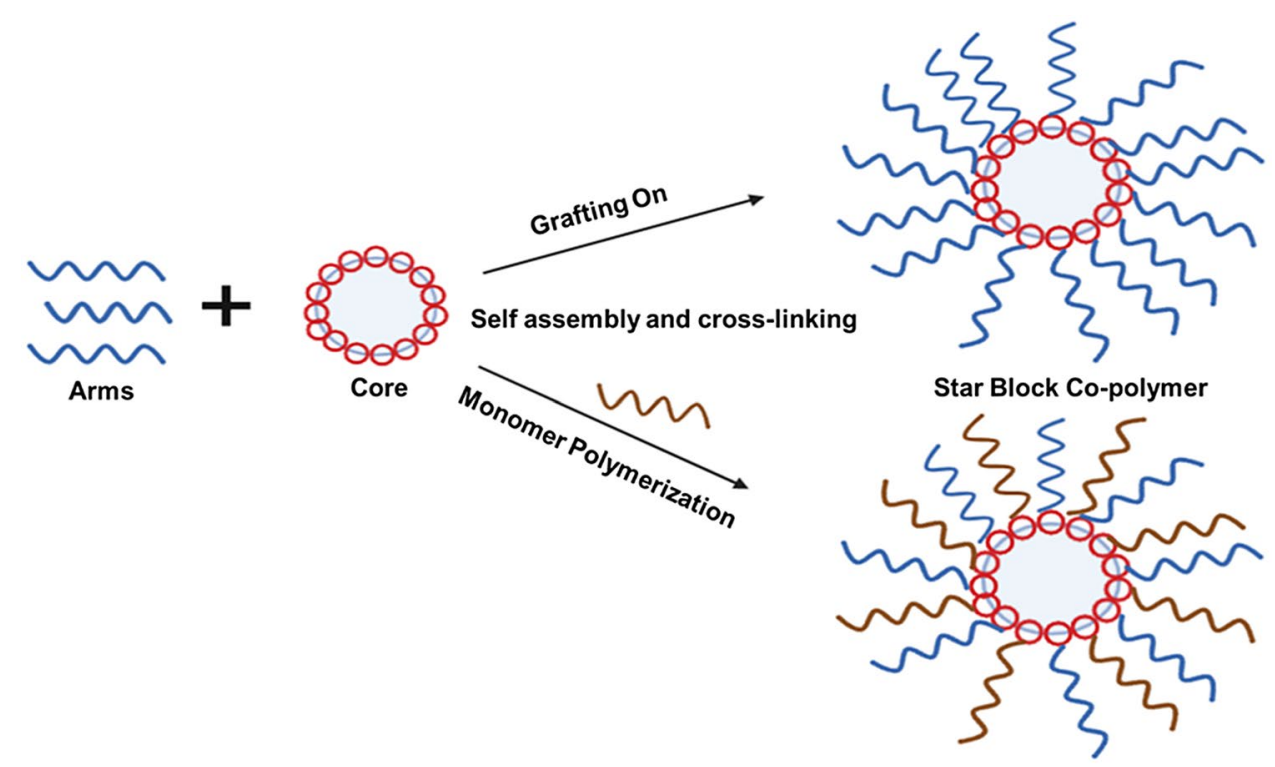




\section{Ring-opening polymerization (ROP)}

This method involves ROP of cyclic esters and derivatives or N-carboxy anhydride where the later one has been proved to be a more flexible and controls chain-growth polymerization technique for the synthesis of peptide polymers having antimicrobial properties. This method relies on employing amino acids as building blocks to obtain polymers having a close structural resemblance to naturally occurring peptides and proteins, hence specific functionalities can be easily incorporated into polypeptide materials. This approach enables preparing synthetically challenging high molecular weight biopolymers which are better compared to other polymers. Improvements in NCA-ROP have shown a superficial direction for the synthesis of distinct peptide polymers with complex macromolecular architectures, like star polymer nanoparticles though they cannot compete with specific peptide orders attained by solid-phase peptide synthesis (Hawker et al. 2001; Nicolas et al. 2013).

Ring-Opening Metathesis Polymerization (ROMP) is the modified form of the ROP technique that operates by opening the cyclic construction, discharging the ring strain of the monomer, and introducing the monomer into the budding chain. The main advantages of this method include easy flexibility, faster reaction rate, negligible side reactions, and very simple end-group modification (Mota et al. 2013).

\section{Reversible addition - fragmentation chain transfer (RAFT) polymerization}

RAFT polymerization is an extremely flexible method for the synthesis of functional macromolecules with highly complicated topological designs such as multiblock, hyperbranched, gradient, star, and many more. The efficiency of the chain transfer process and the synthesis of RAFT play an important role in influencing the structural integrity of the final polymer like chain-end fidelity and polymer dispersity. Steric congestion acts as a chief feature in the outcome that influences the trials such as addition and fragmentation along with the numerous categories of impurities (Wang et al. 2014; Fischer et al. 2015).

\section{Atom transfer radical polymerization (ATRP)}

ATRP is a method of transition metal-mediated controlled radical polymerization that permits the synthesis of diverse functional polymers with required molecular weights and low disparities (Solomon 2005; Boyer et al. 2011; Moad et al. 2012). The synthesis of brush, comb, SNAPPs, and others have been very well demonstrated and exhibits notable considerations by polymer-researchers with the adaptation of core first, arm-first, or grafting-onto strategies (Sulistio et al. 2011, 2012). A novel group of star polymer shows single-molecule stars made by the intermolecular folding followed by the cross-linking of random copolymers to stabilize "brush-like" structures that act as star arms and hydrophobic moieties that drive the self-folding. But others are for polymerization by post functionalization into vinyl groups to act as a cross-linking point (Liu et al. 2012).

\section{Nitroxide-mediated living radical polymerization (NMP)}

NMP is an old method that has exceptional characteristics like being metal and catalyst-free along with bearable functionalities. Yet, currently, it is not much under use due to its fragile maintenance for the end group and also requires high temperature $\left(>100^{\circ} \mathrm{C}\right)$ for the reaction to occur (Nakayama 2012; Byrne et al. 2012, 2013; Lam et al. 2016a).

From various studies, the following general observations are drawn from the characterization data of synthesized SNAAPs.

- Star-shaped SNAPPs with different arm numbers having medium (M) range arm length which was designed in preference to studying the effect of arm number on antimicrobial performance. They exhibited comparable results to the expected values.

- Star-shaped SNAPPs molecular weight is found to be directly proportional to arm number and the hydrodynamic diameter of the stars was also observed to be slightly increasing with arm number.

- Stars with varying arm lengths (S, M, L and VL) have been studied with different degrees of polymerization values. There is an increase in molecular weight and a slight increase in hydrodynamic diameters.

- The surface charge values exhibited similar values obtained across the SNAPPs prepared. Further, any increase in arm number and arm length of the SNAPPs is also found to be increasing with the size of the SNAPPs (Nguyen et al. 2011; Afacan et al. 2012). Figure 5 gives schematic illustration of the arm length of SNAPPs.

\section{Mechanism of action of SNAPPs}

SNAPPs act through a unique, multimodal mechanism involving lipopolysaccharide (LPS) targeting, destabilization /fragmentation of outer membrane, and unregulated ion movements across the membranes in many Gram-negative pathogens, including MDR bacteria. This movement results in membrane disruption along with hyperpolarisation and depolarization of the membrane followed by oxidative stress and production of reactive oxygen species (ROS) (Kohanski et al. 2010). This again is influenced by the arm number and arm length of each SNAPPs. They work literally by tearing 
Fig. 5 Mechanism of action involved in use of SNAPPs

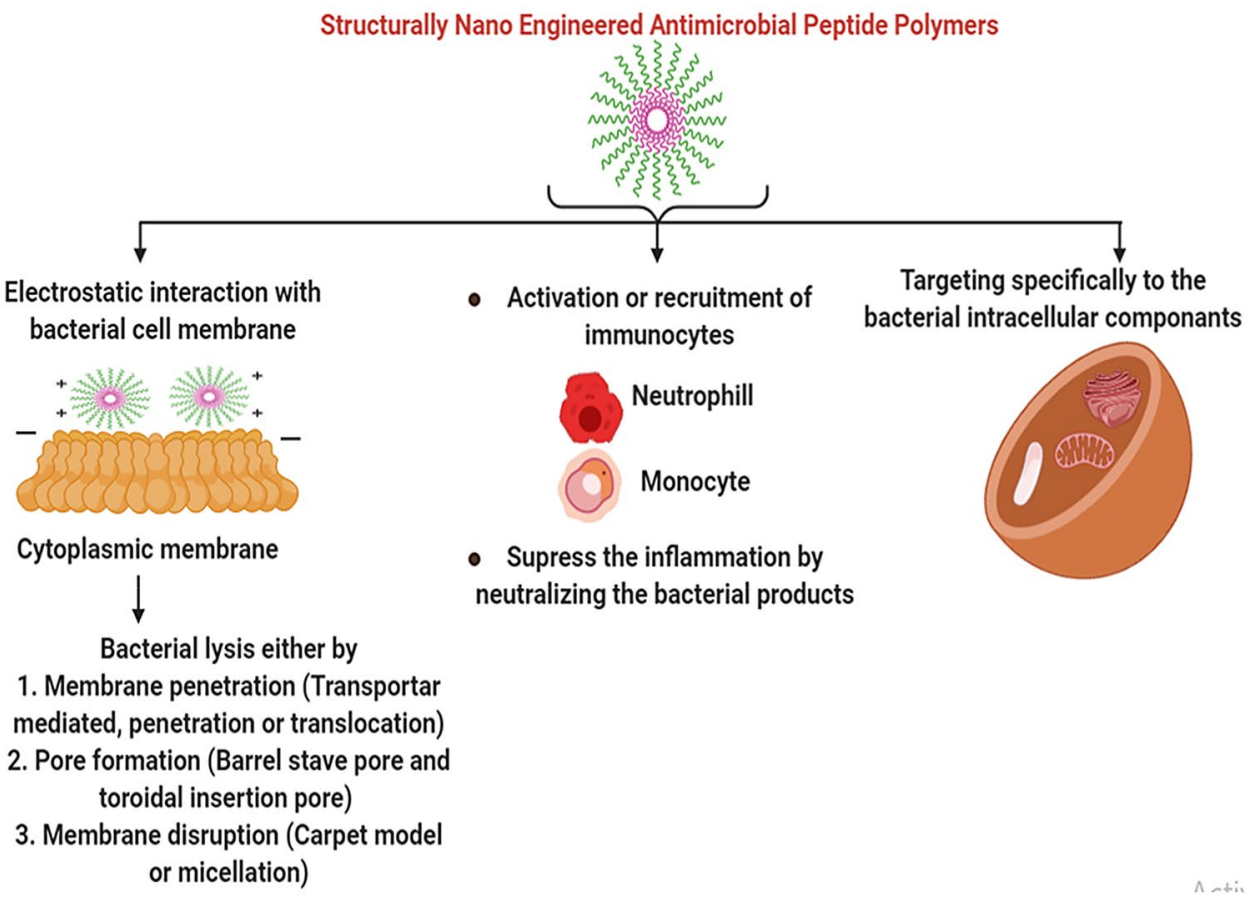

cell wall cytoplasmic membrane apart, thus leading to cell death (Lam et al. 2016a).

\section{Applications of SNAPPs}

In recent years, star-shaped nanopolymers and their widespread applications gained more attention among researchers owing to their enhanced stability, biocompatibility, and therapeutic efficiency. They are proved to display a wide range of applications including targeted drug delivery (Sulistio et al. 2011), gene therapy (Lam et al. 2014), bioimaging (Wang et al. 2014), tissue engineering (Mota et al. 2013), and many more. Some of the important and popular applications of SNAPPs are discussed below.

\section{Antibiotic adjuvant therapy}

One of the successful solutions to overcome MDR bacterial infections is to follow synergistic therapy involving coadministration of SNAPPs with other drugs to achieve maximal therapeutic efficacy. This is a promising and economical solution for bacterial infections to surmount the inadequacies of antibiotic immunotherapy and is being extensively used to treat many health disorders including cancer, tuberculosis, and viral infections (Bozkurt-Guzel et al. 2014; Mohamed et al. 2014; Zhang et al. 2014; Namivandi-Zangeneh et al. 2019). Synergistic therapy plays significant roles such as minimizing acquisition of bacterial resistance (NguSchwemlein et al. 2015; De Gier et al. 2016) re-sensitizing
MDR bacteria to antibiotics (Goldberg et al. 2013; Amani et al. 2015) and negligible toxic profile (Khalil et al. 2008).

The earlier attempt to combine colistin with another antibiotic to overcome MDR Gram-negative infections was highly unsuccessful due to the emergence of resistant strains. To overcome this problems, SNAPPs were combined synergistically with another drug like ampicillin or gentamicin or silver $(\mathrm{Ag}+)$ ions to show counter action against many Gram-negative pathogens. All of them have registered minimum bactericidal concentrations with superior antibacterial efficacies. Further investigation was performed with the synergy of SNAPPs with Doxycycline (Alkawash et al. 1999; Beringer et al. 2012), Imipenem (Rodríguez-Martínez et al. 2009), Tobramycin (De Gier et al. 2016), and so on. All of them were proved to be exhibiting outstanding results with an increase in efficacy compared to when they are administered alone.

SNAPPs have shown great effectiveness against almost all Gram-negative bacteria with the addition of infections that occurred due to CMDR Acinetobacter baumannii. The bacteria did not show any acquisition of resistance to the SNAPPs. SNAPPs showed the death of the bacterial cells by a multimodal mechanism like the destabilization of the outer cell membrane, unregulated movement of ions across the cytoplasmic membrane and apoptotic-like death pathway induction. Its low cost and great effectiveness make it a powerful weapon for combating various MDR bacteria (Lam et al. 2016b).

Star-shaped nanoparticles were prepared by Lam et al. (2016), using SNAPPs and also, bio-nano interaction was 
studied. Anti-microbial activity of SNAPPs against various Gram-negative pathogen in the different medium was also evaluated to mimic the in vivo conditions. An antagonistic effect was observed in the presence of proteins and salts on the SNAPPs anti-microbial efficacy (Lam et al. 2016c). The relationship between the structure and activity of the SNAPPs was studied for setting the basis for future SNAPPs design and development with improved biological activity. The library of SNAPPs was synthesized by varying the length of arms and their number which can be the prime requirement and investigated for its biocompatibility and the biological antimicrobial activity by performing the antimicrobial assays to examine the mechanism of pathogenic bacteria killing or disruption. An increase in arm length and its number increases its effectiveness, which may be due to the availability of polypeptide arms local concentration with higher alfa-helical content. But meanwhile, it increases the toxicity. Based on calculations of the therapeutic index, it was identified that the polypeptide with 4 -arm to 16-arm as best therapeutic moiety. No systemic damage was observed when evaluated for the biocompatibility of SNAPPs with biological activity in mice (Shirbin et al. 2018).

\section{Drug delivery systems}

Due to various problems associated with the delivering pure drug as such, generation of drug carrier which improves the activity of drug by encapsulating it and targeting to the required site. In that, over the past few decades development of well-designed SNAPPs as competent functional encapsulation tools for drug molecules has been a special area of interest (Haag 2004; Torchilin 2007; Peer et al. 2007). SNAPPs have been utilized as the carriers for delivering the guest or drug moieties owing to their unique structural and chemical characteristics. In general, these devices are nonpolar molecules and can be loaded in the hydrophobic core surrounded by a hydrophilic stabilizing crust. SNAPPs with more arm numbers can function as unimolecular drug carriers while using for encapsulation as they do not undergo disintegration into individual polymer under the changes in conditions like $\mathrm{pH}$, ionic strength, and high dilution (Gao 2012) and these are outstandingly stable. Further, the length and block ratio of the arms in these structures can be conveniently regulated. These unique features of SNAPPs make them helpful to achieve effective drug encapsulation and controlled drug release.

Multifunctional integrated systems for encapsulation and drug delivery could be facilitated by introducing different targeting groups into the periphery of SNAPPs where hyperbranched or multifunctional structures provided better results for this purpose (Xiao et al. 2012; Zhao et al. 2013b; Wu et al. 2015). Antineoplastic agents like paclitaxel (Duan et al. 2017), doxorubicin (Schramm et al. 2009) and hydrochlorthiazide (Chen et al. 2011) were successfully encapsulated with superior drug loading content and loading efficiency and there is better cell uptake by tumor tissues. SNAPPs have been proved as effective drug carriers and applicable mainly for sustained, controlled and targeted drug delivery (Wu et al. 2015). This is because of their special characteristics like the solubilizing ability of hydrophobic drugs, high molecular weight, targeting particular physiological sites and easy controlling rate of drug release (Salata 2007). A large number of macromolecules with a high degree of functionality have been prepared and employed as drug delivery vehicles that are capable of reducing the dosage requirements along with minimal undesirable side effects of the drug.

Compared to block copolymer micelles and dendrimers, the use of SNAPPs has registered more efficiency and applications in drug delivery (Wu et al. 2015). These copolymers get self-assembled in aqueous media to form micelle structures in which hydrophobic core domains are enclosed by a hydrophilic periphery. The core domine is capable to solubilize hydrophobic drug molecules while the hydrophilic region is to solubilize the particles in aqueous media. Further, SNAPPs have other advantages as they can also provide an alternative route for drug administration and convenient to administer drugs orally or parenterally. Demonstration on encapsulation of doxorubicin in SNAPPs was performed in which the drug was made to conjugate with the aldehyde groups in the star core via an imine linkage and resulting in controlled release of the drug at lower $\mathrm{pH}$ (Nasr et al. 2015). It was shown that the SNAPPs could accumulate better in the tumour cell with longer plasma circulation time and confirmed that these polymers potential enough for improved delivery of therapeutic agents in vivo. Drugs such as paclitaxel (Duan et al. 2017), progesterone (Jones et al. 2003), furosemide (Schramm et al. 2009), hydrochlorthiazide (Chen et al. 2011), etoposide (Wang et al. 2005) and 5-fluorouracil (Aryal et al. 2009) have also been successfully encapsulated in the core of SNAPPs to explore their releasing efficiencies.

Moreover, this type of delivery system must be stable during systemic circulation in blood to minimise the leakage of the encapsulated drug before reaching the target tissue and this depends again on the local environment (Chen et al. 2008; Cabral and Kataoka 2010). Later, active targeting by functionalizing drug carriers with antibodies, peptides and small molecules have been adapted to improve efficiency which can distinguish exact receptors in pathological tissues and there is a severe reduction in adverse effects observed (Prabaharan et al. 2009; Yang et al. 2010).

\section{For gene delivery}

Various genetic disorders like cancer, diabetes, blindness, cystic fibrosis and parkinson's disease can be treated 
successfully with the application of gene therapy (Grigsby and Leong 2010). Therapy or treatment provided by this mode is dependent on the delivery of genetic materials such as plasmid DNA, siRNA and microRNA into cells, as these negatively charged hydrophilic materials cannot efficiently pass through hydrophobic membranes which are also negatively charged. Further, these materials can undergo enzymatic degradations before reaching the nucleus; hence it is necessary to encapsulate them (Hancock and Sahl 2006; Zhou et al. 2010). The earlier attempts to use viral carrier vectors for encapsulation were unsuccessful clinically due to various reasons like possible immune responses, the amount and size of genetic materials and high production cost. Hence, the cationic SNAPPs have been employed as transfection vectors to complex electrostatically with the negatively charged nucleic acids. The aqueous solubility and biocompatibility were improved with polyethylene glycol (PEG) as a common chemical group connected to polymeric vectors (Cloninger 2002) which depends upon molecular weight, architecture, degree of branching, and charge density of SNAPPs.

An extensive study on gene therapy in relation to SNAPPs based on peptide-functionalized polymers or polypeptides has been carried out by many research teams (Fichter et al. 2008; Zhao et al. 2013a) and the results were documented in terms of size and surface charges that the star-shaped polymers can complex efficiently compared to the linear ones. It was also showed that the size of polymers plays a major role in systemic and intratumoral distributions with their size range of 10-30 nm exhibiting deep tissue penetration (Lee et al. 2010; Tang et al. 2012) and decreased blood clearance (Perrault et al. 2009).

Newer type core-shell SNAPPs have also been synthesized which can complex with many nucleic acid molecules. The chain extension with PEG on star polymer having $\mathrm{N}$-(2-aminoethyl) methacrylamide hydrochloride (AEMA. $\mathrm{HCl}$ ) cationic core has displayed better colloidal stability, neutral zeta potentials and minor cellular toxicity which provides a modified carrier for efficient siRNA delivery. SNAPPs that can respond to stimuli like pH (Kim et al. 2009; Guo et al. 2010), redox potential (Kamada et al. 2010; Terashima et al. 2014, 2015), light (Nyström et al. 2011; Boyer et al. 2012), temperature (Tan et al. 2014; McKenzie et al. 2016) and enzymatic changes (Byrne et al. 2012; Thornton et al. 2013) have been recently developed and one of the popular area for targeted drug and gene delivery applications.

\section{Interfacial stabilizing agents}

Recent studies suggest that SNAPPs having many arms and a crowdedly cross-linked core are established as efficient interfacial stabilizing agents for emulsion systems (Qiu et al.
2011; Li et al. 2012). The flexible polymeric chains spread out from the central core can be readily deformed and can act as either pickering stabilizers (particle-like) or established asymmetric surfactants (molecule-like) (Binks and Lumsdon 2001). When demixing of the arm occurs from solubility differences, traditional asymmetric type structures are formed in the form of much larger sized spheres having characteristics of surfactant. Hence, SNAPPs can be stimuli-responsive which can distinguish a stable emulsion from an unstable state. Reversible emulsification demulsification processes on stimuli-responsive core cross-linked star (CCS) polymers have been studied and shown that the thermoresponsive nature of these polymers is accountable for thermally triggered demulsification of polymer-stabilized emulsions (Binks and Lumsdon 2001). This sort of control and adjustability over temperature for destabilization can be conveniently applicable in environments like targeted drug delivery.

The conversion of W/O system into O/W type and vice versa depends mainly upon $\mathrm{pH}$. At lower $\mathrm{pH}$, the arms are more protonated, become cationic, and prefer their higher solubility in water and lesser in an oil phase. Hence the formation of $\mathrm{O} / \mathrm{W}$ emulsion is favoured where the polymers go mainly into the aqueous continuous phase (Golemanov et al. 2006). With an increase in $\mathrm{pH}$, there is a preferential formation of W/O type emulsion. It was also demonstrated that stabilization of emulsions can be possible at a very low concentration of polymers and in particular, SNAPPs which are larger with more radiating arms could stabilize emulsions at lower concentrations efficiently. These parameters are highly helpful to overcome the formulation problems in the study of emulsions.

\section{Bioimaging}

By following the biodistribution and targeting efficiency of a drug delivery system, an in vivo studies have been performed to know the cell migration and nature of the disease. An imaging with clinical diagnostic methods/agents help in assessing the state and extent of the disease before deciding for initial therapy (Adkins et al. 2012). The distinctive properties and structural characteristics of SNAPPs make them appropriate as fluorescent explorers, contrast agents and in vitro diagnostic systems (Fukukawa et al. 2008; Wang et al. 2012; Bagby et al. 2012).

To determine the effect of SNAPPs on Gadolinium Magnetic Resonance Imaging $\left(\mathrm{Gd}^{3+} \mathrm{MRI}\right)$ contrast agents, macromolecular ligands were chelated to complex $\mathrm{Gd}^{3+}$ and the results were compared by studying reflexivity properties (Li et al. 2012). The star nano gel exhibited a relaxation rate much higher than in the commercial $\mathrm{Gd}^{3+}$ MRI contrast product. Poly acrylate-based SNAPPs with bimodal imaging agents which is the combination of fluorescent and magnetic 
resonance features have also been developed (Adkins et al. 2012). Later, SNAPPs were structurally altered with dopamine analogs and made into chelate formation with lanthanides like $\mathrm{Gd}^{3+}$ and $\mathrm{Eu}^{3+}$. High molecular weight polymer drug carriers with branched star-like structural design have been proved to exhibit higher accumulation in tumor tissues due to better permeability and retention effect (Ulbrich et al. 2003; Etrych et al. 2008).

\section{Summary and future prospectives}

Currently, SNAPPs, in the form of star-shaped polymers present an emerging novel approach for the treatment of various infections associated with antimicrobial resistance. The unique properties of SNAPPs make them more successful and widely acceptable for the various applications of the pharmaceutical field and also help in delivering the drug molecules with minimal toxicity and greater therapeutic effect. In the current review, we have covered the detailed synthesis and mechanism behavior of the SNAPPs. Also, various novel applications of SNAPPs are included by discussing the case studies.

In the future, with the help of various approaches, the effective, less toxic and nanomaterial sized SNAPPs can be given priority to provide permanent solutions for microbial resistance developed infections. Though having many advantages over other polymers and formulations, the commercial utility of these precious SNAPPs is awarded less attention. More focus can be provided for their commercial value from researchers by keeping parallel coordination with those from other disciplines and industries. It is highly necessary to continue extensive research in the development of efficient star-polymers to acquire highly economical and still better reproducible outcomes. Further modulations of functionalities in SNAPPs development and their role in therapeutic value with minimal impurities and utility in many other important fields can be kept as a futuristic goal for the forthcoming research activities.

Acknowledgements The authors would like to express their sincere gratitude to Manipal Academy of Higher Education, Manipal, for providing facilities for the literature search and other facilities. Authors are also thankful to the Indian Council of Medical Research (ICMR), New Delhi, Ref. No 35/13/020-Nano/BMS for the fund support.

Funding Open access funding provided by Manipal Academy of Higher Education, Manipal. Fund support by Indian Council of Medical Research (ICMR), New Delhi, Ref. No 35/13/020-Nano/BMS to work in this area.

\section{Declarations}

Conflict of interest The authors declare that they have no conflict of interest.

Open Access This article is licensed under a Creative Commons Attribution 4.0 International License, which permits use, sharing, adaptation, distribution and reproduction in any medium or format, as long as you give appropriate credit to the original author(s) and the source, provide a link to the Creative Commons licence, and indicate if changes were made. The images or other third party material in this article are included in the article's Creative Commons licence, unless indicated otherwise in a credit line to the material. If material is not included in the article's Creative Commons licence and your intended use is not permitted by statutory regulation or exceeds the permitted use, you will need to obtain permission directly from the copyright holder. To view a copy of this licence, visit http://creativecommons.org/licenses/by/4.0/.

\section{References}

Adkins CT, Dobish JN, Brown CS et al (2012) High relaxivity MRI imaging reagents from bimodal star polymers. Polym Chem 3:390-398. https://doi.org/10.1039/c1py00474c

Afacan J, Yeung NTY, Pena AM, Hancock OEW (2012) Therapeutic potential of host defense peptides in antibiotic-resistant infections. Curr Pharm Des 18:807-819. https://doi.org/10.2174/ 138161212799277617

Alkawash M, Head M, Alshami I, Soothill JS (1999) The effect of human lactoferrin on the MICs of doxycycline and rifampicin for Burkholderia cepacia and Pseudomonas aeruginosa strains. J Antimicrob Chemother 44:385-387. https://doi.org/10.1093/ jac/44.3.385

Amani J, Barjini K, Moghaddam M, Asadi A (2015) In vitro synergistic effect of the CM11 antimicrobial peptide in combination with common antibiotics against clinical isolates of six species of multidrug-resistant pathogenic bacteria. Protein Pept Lett 22:940-951. https://doi.org/10.2174/09298665226661507281 15439

Aryal S, Prabaharan M, Pilla S, Gong S (2009) Biodegradable and biocompatible multi-arm star amphiphilic block copolymer as a carrier for hydrophobic drug delivery. Int J Biol Macromol 44:346-352. https://doi.org/10.1016/j.ijbiomac.2009.01.007

Bagby TR, Duan S, Cai S et al (2012) Lymphatic trafficking kinetics and near-infrared imaging using star polymer architectures with controlled anionic character. Eur J Pharm Sci 47:287-294. https://doi.org/10.1016/j.ejps.2012.04.016

Bapat AP, Ray JG, Savin DA et al (2012) Dynamic-covalent nanostructures prepared by Diels-Alder reactions of styrene-maleic anhydride-derived copolymers obtained by one-step cascade block copolymerization. Polym Chem 3:3112-3120. https://doi. org/10.1039/c2py20351k

Bechinger B, Gorr SU (2017) Antimicrobial peptides: mechanisms of action and resistance. J Dent Res 96:254-260. https://doi.org/10. 1177/0022034516679973

Beringer PM, Owens H, Nguyen A et al (2012) Pharmacokinetics of doxycycline in adults with cystic fibrosis. Antimicrob Agents Chemother 56:70-74. https://doi.org/10.1128/AAC.05710-11

Binks BP, Lumsdon SO (2001) Pickering emulsions stabilized by monodisperse latex particles: Effects of particle size. Langmuir 17:4540-4547. https://doi.org/10.1021/la0103822

Boucher HW, Talbot GH, Bradley JS et al (2009) Bad bugs, no drugs: No ESKAPE! An update from the infectious diseases society 
of America. Clin Infect Dis 48:1-12. https://doi.org/10.1086/ 595011

Boyer C, Derveaux A, Zetterlund PB, Whittaker MR (2012) Synthesis of multi-block copolymer stars using a simple iterative $\mathrm{Cu}(0)$ mediated radical polymerization technique. Polym Chem 3:117123. https://doi.org/10.1039/c1py00384d

Boyer C, Stenzel MH, Davis TP (2011) Building nanostructures using RAFT polymerization. J Polym Sci Part A Polym Chem 49:551595. https://doi.org/10.1002/pola.24482

Bozkurt-Guzel C, Savage PB, Akcali A, Ozbek-Celik B (2014) Potential synergy activity of the novel ceragenin, CSA-13, against carbapenem-resistant aCinetobacter baumannii strains isolated from bacteremia patients. Biomed Res Int 2014:710273. https:// doi.org/10.1155/2014/710273

Brown ED, Wright GD (2016) Antibacterial drug discovery in the resistance era. Nature 529:336-343. https://doi.org/10.1038/ nature 17042

Byrne M, Thornton PD, Cryan SA, Heise A (2012) Star polypeptides by NCA polymerisation from dendritic initiators: synthesis and enzyme controlled payload release. Polym Chem 3:2825-2831. https://doi.org/10.1039/c2py20327h

Byrne M, Victory D, Hibbitts A et al (2013) Molecular weight and architectural dependence of well-defined star-shaped poly(lysine) as a gene delivery vector. Biomater Sci 1:12231234. https://doi.org/10.1039/c3bm60123d

Cabral H, Kataoka K (2010) Multifunctional nanoassemblies of block copolymers for future cancer therapy. Sci Technol Adv Mater 11:014109. https://doi.org/10.1088/1468-6996/11/1/ 014109

Chen B, Van Der Poll DG, Jerger K et al (2011) Synthesis and properties of star-comb polymers and their doxorubicin conjugates. Bioconjug Chem 22:617-624. https://doi.org/10.1021/bc100 $400 \mathrm{u}$

Chen S, Zhang XZ, Cheng SX et al (2008) Functionalized amphiphilic hyperbranched polymers for targeted drug delivery. Biomacromol 9:2578-2585. https://doi.org/10.1021/bm800371n

Chen WY, Chang HY, Lu JK et al (2015) Self-assembly of antimicrobial peptides on gold nanodots: against multidrug-resistant bacteria and wound-healing application. Adv Funct Mater 25:7189-7199. https://doi.org/10.1002/adfm.201503248

Cheng J, Deming TJ (2012) Synthesis of polypeptides by ring-opening polymerization of $\alpha$-Amino acid $\mathrm{N}$-carboxyanhydrides. Top Curr Chem 310:1-26. https://doi.org/10.1007/128_2011_173

Cloninger MJ (2002) Biological applications of dendrimers. Curr Opin Chem Biol 6:742-748. https://doi.org/10.1016/S13675931(02)00400-3

De Gier MG, Bauke Albada H, Josten M et al (2016) Synergistic activity of a short lipidated antimicrobial peptide (lipoAMP) and colistin or tobramycin against Pseudomonas aeruginosa from cystic fibrosis patients. Medchemcomm 7:148-156. https://doi.org/10.1039/c5md00373c

Deslouches B, Islam K, Craigo JK et al (2005) Activity of the de novo engineered antimicrobial peptide WLBU2 against Pseudomonas aeruginosa in human serum and whole blood: Implications for systemic applications. Antimicrob Agents Chemother 49:3208-3216. https://doi.org/10.1128/AAC.49.8. 3208-3216.2005

Duan R, Li C, Wang F, Yangi JC (2017) Polymer-lipid hybrid nanoparticles-based paclitaxel and etoposide combinations for the synergistic anticancer efficacy in osteosarcoma. Colloids Surfaces B Biointerfaces 159:880-887. https://doi.org/10.1016/j. colsurfb.2017.08.042

Etrych T, Chytil P, Mrkvan T et al (2008) Conjugates of doxorubicin with graft HPMA copolymers for passive tumor targeting. J Control Release 132:184-192. https://doi.org/10.1016/j.jconrel. 2008.04.017
Fichter KM, Zhang L, Kiick KL, Reineke TM (2008) Peptide-functionalized poly(ethylene glycol) star polymers: DNA delivery vehicles with multivalent molecular architecture. Bioconjug Chem 19:76-88. https://doi.org/10.1021/bc0701141

Fischer CS, Jenewein C, Mecking S (2015) Conjugated star polymers from multidirectional Suzuki-Miyaura polymerization for live cell imaging. Macromolecules 48:483-491. https://doi.org/10. 1021/ma502294n

Fukukawa KI, Rossin R, Hagooly A et al (2008) Synthesis and characterization of core-shell star copolymers for in vivo PET imaging applications. Biomacromol 9:1329-1339. https://doi.org/10. 1021/bm7014152

Gao H (2012) Development of star polymers as unimolecular containers for nanomaterials. Macromol Rapid Commun 33:722-734. https://doi.org/10.1002/marc.201200005

Gill EE, Franco OL, Hancock REW (2015) Antibiotic adjuvants: diverse strategies for controlling drug-resistant pathogens. Chem Biol Drug Des 85:56-78. https://doi.org/10.1111/cbdd.12478

Goldberg K, Sarig H, Zaknoon F et al (2013) Sensitization of gramnegative bacteria by targeting the membrane potential. FASEB J 27:3818-3826. https://doi.org/10.1096/fj.13-227942

Golemanov K, Tcholakova S, Kralchevsky PA et al (2006) Latexparticle-stabilized emulsions of anti-bancroft type. Langmuir 22:4968-4977. https://doi.org/10.1021/la0603875

Grigsby CL, Leong KW (2010) Balancing protection and release of DNA: Tools to address a bottleneck of non-viral gene delivery. J R Soc Interface 7:S82. https://doi.org/10.1098/rsif.2009.0260

Guo Z, Chen X, Xin J et al (2010) Effect of molecular weight and arm number on the growth and $\mathrm{pH}$-dependent morphology of star poly[2-(dimethylamino)ethyl methacrylate]/ poly(styrenesulfonate) multilayer films. Macromolecules 43:9087-9093. https://doi.org/10.1021/ma1013429

Haag R (2004) Supramolecular drug-delivery systems based on polymeric core-shell architectures. Angew Chemie - Int Ed 43:278-282. https://doi.org/10.1002/anie.200301694

Håkansson J, Ringstad L, Umerska A et al (2019) Characterization of the in vitro, ex vivo, and in vivo efficacy of the antimicrobial peptide dpk-060 used for topical treatment. Front Cell Infect Microbiol 9:174. https://doi.org/10.3389/fcimb.2019.00174

Hawker CJ, Bosman AW, Harth E (2001) New polymer synthesis by nitroxide mediated living radical polymerizations. Chem Rev 101:3661-3688. https://doi.org/10.1021/cr990119u

Huan Y, Kong Q, Mou H, Yi H (2020) Antimicrobial peptides: classification, design, application and research progress in multiple fields. Front Microbiol 11:2559. https://doi.org/10.3389/fmicb. 2020.582779

Isono T, Kondo Y, Otsuka I et al (2013) Synthesis and stereocomplex formation of star-shaped stereoblock polylactides consisting of poly(1-lactide) and poly(d -lactide) Arms. Macromolecules 46:8509-8518. https://doi.org/10.1021/ma401375x

Jain A, Duvvuri LS, Farah S, Beyth N, Domb AJ, Khan W (2014) Antimicrobial polymers. Adv Healthcare Mater 3(12):19691985. https://doi.org/10.1002/adhm.201400418

Jones MC, Ranger M, Leroux JC (2003) pH-sensitive unimolecular polymeric micelles: synthesis of a novel drug carrier. Bioconjug Chem 14:774-781. https://doi.org/10.1021/bc020041f

Kamada J, Koynov K, Corten C et al (2010) Redox responsive behavior of thiol/disulfide-functionalized star polymers synthesized via atom transfer radical polymerization. Macromolecules 43:4133-4139. https://doi.org/10.1021/ma100365n

Khalil H, Chen T, Riffon R et al (2008) Synergy between polyethylenimine and different families of antibiotics against a resistant clinical isolate of Pseudomonas aeruginosa. Antimicrob Agents Chemother 52:1635-1641. https://doi.org/10.1128/ AAC.01071-07 
Kim BS, Gao H, Argun AA et al (2009) All-star polymer multilayers as pH-responsive nanofilms. Macromolecules 42:368-375. https://doi.org/10.1021/ma801812v

Kohanski MA, Dwyer DJ, Collins JJ (2010) How antibiotics kill bacteria: From targets to networks. Nat Rev Microbiol 8:423-435. https://doi.org/10.1038/nrmicro2333

Lam SJ, O'Brien-Simpson NM, Pantarat N et al (2016a) Combating multidrug-resistant Gram-negative bacteria with structurally nanoengineered antimicrobial peptide polymers. Nat Microbiol 1:16162. https://doi.org/10.1038/nmicrobiol.2016.162

Lam SJ, O'Brien-Simpson NM, Pantarat N et al (2016b) Combating multidrug-resistant Gram-negative bacteria with structurally nanoengineered antimicrobial peptide polymers. Nat Microbiol 1:1-11. https://doi.org/10.1038/nmicrobiol.2016.162

Lam SJ, Sulistio A, Ladewig K et al (2014) Peptide-based star polymers as potential siRNA carriers. Aust J Chem 67:592. https:// doi.org/10.1071/CH13525

Lam SJ, Wong EHH, O'Brien-Simpson NM et al (2016) Bionano interaction study on antimicrobial star-shaped peptide polymer nanoparticles. ACS Appl Mater Interfaces 8:33446-33456. https://doi.org/10.1021/acsami.6b11402

Lee H, Fonge H, Hoang B et al (2010) The effects of particle size and molecular targeting on the intratumoral and subcellular distribution of polymeric nanoparticles. Mol Pharm 7:1195-1208. https://doi.org/10.1021/mp100038h

Li W, Yu Y, Lamson M et al (2012) PEO-based star copolymers as stabilizers for water-in-oil or oil-in-water emulsions. Macromolecules 45:9419-9426. https://doi.org/10.1021/ma3016773

Liu J, Duong H, Whittaker MR et al (2012) Synthesis of functional core, star polymers via RAFT polymerization for drug delivery applications. Macromol Rapid Commun 33:760-766. https://doi. org/10.1002/marc.201200029

Mahlapuu M, Håkansson J, Ringstad L, Björn C (2016) Antimicrobial peptides: An emerging category of therapeutic agents. Front Cell Infect Microbiol 6:194. https://doi.org/10.3389/fcimb.2016. 00194

McKenzie TG, Ren JM, Dunstan DE et al (2016) Synthesis of highorder multiblock core cross-linked star polymers. J Polym Sci Part A Polym Chem 54:135-143. https://doi.org/10.1002/pola. 27775

Moad G, Rizzardo E, Thang SH (2012) Living radical polymerization by the RAFT process a third update. Aust J Chem 65:985-1076. https://doi.org/10.1071/CH12295

Mohamed MF, Hammac GK, Guptill L, Seleem MN (2014) Antibacterial activity of novel cationic peptides against clinical isolates of multi-drug resistant Staphylococcus pseudintermedius from infected dogs. PLoS One 9:e116259. https://doi.org/10.1371/ journal.pone.0116259

Mota C, Puppi D, Dinucci D et al (2013) Additive manufacturing of star poly( $\varepsilon$-caprolactone) wet-spun scaffolds for bone tissue engineering applications. J Bioact Compat Polym 28:320-340. https://doi.org/10.1177/0883911513490341

Mukhopadhyay S, Bharath Prasad AS, Mehta CH, Nayak UY (2020) Antimicrobial peptide polymers: no escape to ESKAPE pathogens-a review. World J Microbiol Biotechnol 36:1-4. https:// doi.org/10.1007/s11274-020-02907-1

Nakayama Y (2012) Hyperbranched polymeric "star vectors" for effective DNA or siRNA delivery. Acc Chem Res 45:994-1004. https://doi.org/10.1021/ar200220t

Namivandi-Zangeneh R, Sadrearhami Z, Dutta D et al (2019) Synergy between synthetic antimicrobial polymer and antibiotics: a promising platform to combat multidrug-resistant bacteria. ACS Infect Dis 5:1357-1365. https://doi.org/10.1021/acsinfecdis.9b00049

Nasr M, Ghorab MK, Abdelazem A (2015) In vitro and in vivo evaluation of cubosomes containing 5-fluorouracil for liver targeting.
Acta Pharm Sin B 5:79-88. https://doi.org/10.1016/j.apsb.2014. 12.001

$\mathrm{Ng}$ VWL, Ke X, Lee ALZ et al (2013) Synergistic co-delivery of membrane-disrupting polymers with commercial antibiotics against highly opportunistic bacteria. Adv Mater 25:6730-6736. https:// doi.org/10.1002/adma.201302952

Ngu-Schwemlein M, Dumond J, Rudd L, Rigaud J-H (2015) In vitro synergy between some cationic amphipathic cyclooctapeptides and antibiotics. Aust J Chem 68:218-223. https://doi.org/10. 1071/CH14427

Nguyen LT, Haney EF, Vogel HJ (2011) The expanding scope of antimicrobial peptide structures and their modes of action. Trends Biotechnol 29:464-472. https://doi.org/10.1016/j.tibtech.2011. 05.001

Nicolas J, Guillaneuf Y, Lefay C et al (2013) Nitroxide-mediated polymerization. Prog Polym Sci 38:63-235. https://doi.org/10. 1016/j.progpolymsci.2012.06.002

Nyström F, Soeriyadi AH, Boyer C et al (2011) End-group fidelity of copper(0)-meditated radical polymerization at high monomer conversion: an ESI-MS investigation. J Polym Sci Part A Polym Chem 49:5313-5321. https://doi.org/10.1002/pola.25010

Peer D, Karp JM, Hong S et al (2007) Nanocarriers as an emerging platform for cancer therapy. Nat Nanotechnol 2:751-760. https:// doi.org/10.1038/nnano.2007.387

Perrault SD, Walkey C, Jennings T et al (2009) Mediating tumor targeting efficiency of nanoparticles through design. Nano Lett 9:1909-1915. https://doi.org/10.1021/n1900031y

Prabaharan M, Grailer JJ, Pilla S et al (2009) Folate-conjugated amphiphilic hyperbranched block copolymers based on Boltorn ${ }^{\circledR} \mathrm{H} 40$, poly(l-lactide) and poly(ethylene glycol) for tumor-targeted drug delivery. Biomaterials 30:3009-3019. https://doi.org/10.1016/j. biomaterials.2009.02.011

Qiu Q, Liu G, An Z (2011) Efficient and versatile synthesis of star polymers in water and their use as emulsifiers. Chem Commun 47:12685-12687. https://doi.org/10.1039/c1cc15679a

Rodríguez-Martínez JM, Poirel L, Nordmann P (2009) Molecular epidemiology and mechanisms of carbapenem resistance in Pseudomonas aeruginosa. Antimicrob Agents Chemother 53:47834788. https://doi.org/10.1128/AAC.00574-09

Rosignoli C, Thibaut de Ménonville S, Orfila D et al (2018) A topical treatment containing heat-treated Lactobacillus johnsonii NCC 533 reduces Staphylococcus aureus adhesion and induces antimicrobial peptide expression in an in vitro reconstructed human epidermis model. Exp Dermatol 27:358-365. https://doi.org/10. $1111 /$ exd.13504

Salata OV (2007) Nanotechnology in therapeutics: hydrogels and beyond. J Nanobiotechnology 5:5. https://doi.org/10.1186/ 1477-3155-5-5

Schramm OG, Meier MAR, Hoogenboom R et al (2009) Polymeric nanocontainers with high loading capacity of hydrophobic drugs\. Soft Matter 5:1662-1668. https://doi.org/10.1039/b8160 $87 \mathrm{~b}$

Shen W, He P, Xiao C, Chen X (2018) From antimicrobial peptides to antimicrobial poly $(\alpha$-amino acid $) \mathrm{s}$. Adv Healthc Mater 7:e1800354. https://doi.org/10.1002/adhm.201800354

Shirbin SJ, Insua I, Holden JA et al (2018) Architectural effects of star-shaped "structurally nanoengineered antimicrobial peptide polymers" (SNAPPs) on their biological activity. Adv Healthc Mater 7:e1800627. https://doi.org/10.1002/adhm.201800627

So MC, Aananth R, Suntres EZ (2020) Determination of Pharmacokinetic parameters of a four-armed, guanidinium-rich structurally nanoengineered antimicrobial peptide polymer: a research protocol. Undergraduate Research in Natural and Clinical Science and Technology Journal 2:1-9 
Solomon DH (2005) Genesis of the CSIRO polymer group and the discovery and significance of nitroxide-mediated living radical polymerization. J Polym Sci Part A Polym Chem 43:5748-5764. https://doi.org/10.1002/pola.21067

Sulistio A, Blencowe A, Widjaya A et al (2012) Development of functional amino acid-based star polymers. Polym Chem 3:224-234. https://doi.org/10.1039/c1py00436k

Sulistio A, Lowenthal J, Blencowe A et al (2011) Folic acid conjugated amino acid-based star polymers for active targeting of cancer cells. Biomacromol 12:3469-3477. https://doi.org/10.1021/ bm200604h

Tan S, Wong EHH, Fu Q et al (2014) Azobenzene-functionalised core cross-linked star polymers and their host-guest interactions. Aust J Chem 67:173-178. https://doi.org/10.1071/CH13425

Tang L, Fan TM, Borst LB, Cheng J (2012) Synthesis and biological response of size-specific, monodisperse drug-silica nanoconjugates. ACS Nano 6:3954-3966. https://doi.org/10.1021/nn300 $149 \mathrm{c}$

Terashima T, Nishioka S, Koda Y et al (2014) Arm-cleavable microgel star polymers: A versatile strategy for direct core analysis and functionalization. J Am Chem Soc 136:10254-10257. https:// doi.org/10.1021/ja505646p

Terashima T, Sugita T, Sawamoto M (2015) Single-chain crosslinked star polymers via intramolecular crosslinking of self-folding amphiphilic copolymers in water. Polym J 47:667-677. https:// doi.org/10.1038/pj.2015.54

Thomson JM, Bonomo RA (2005) The threat of antibiotic resistance in Gram-negative pathogenic bacteria: $\beta$-lactams in peril! Curr Opin Microbiol 8:518-524. https://doi.org/10.1016/j.mib.2005. 08.014

Thornton PD, Billah SMR, Cameron NR (2013) Enzyme-degradable self-assembled hydrogels from polyalanine-modified poly(ethylene glycol) star polymers. Macromol Rapid Commun 34:257-262. https://doi.org/10.1002/marc.201200649

Torchilin VP (2007) Micellar nanocarriers: Pharmaceutical perspectives. Pharm Res 24:1-16. https://doi.org/10.1007/ s11095-006-9132-0

Ulbrich K, Etrych T, Chytil P et al (2003) HPMA copolymers with $\mathrm{pH}$-controlled release of doxorubicin: In vitro cytotoxicity and in vivo antitumor activity. J Control Release 87:33-47. https:// doi.org/10.1016/S0168-3659(02)00348-6

Vayaboury W, Giani O, Cottet $\mathrm{H}$ et al (2004) Living Polymerization of $\alpha$-Amino AcidN-Carboxyanhydrides(NCA) upon Decreasing the Reaction Temperature. Macromol Rapid Commun 25:12211224. https://doi.org/10.1002/marc.200400111

Wang F, Bronich TK, Kabanov AV et al (2005) Synthesis and evaluation of a star amphiphilic block copolymer from poly $(\varepsilon-$ caprolactone) and poly(ethylene glycol) as a potential drug delivery carrier. Bioconjug Chem 16:397-405. https://doi.org/ $10.1021 / \mathrm{bc} 049784 \mathrm{~m}$

Wang K, Peng H, Thurecht KJ et al (2014) Biodegradable core crosslinked star polymer nanoparticles as 19F MRI contrast agents for selective imaging. Polym Chem 5:1760-1771. https:// doi.org/10.1039/c3py01311a

Wang Y, Hong CY, Pan CY (2012) Spiropyran-based hyperbranched star copolymer: Synthesis, phototropy, FRET, and bioapplication. Biomacromol 13:2585-2593. https://doi.org/10.1021/ bm3008346

Wu W, Wang W, Li J (2015) Star polymers: Advances in biomedical applications. Prog Polym Sci 46:55-85. https://doi.org/10.1016/j. progpolymsci.2015.02.002

Xiao Y, Hong H, Javadi A et al (2012) Multifunctional unimolecular micelles for cancer-targeted drug delivery and positron emission tomography imaging. Biomaterials 33:3071-3082. https://doi. org/10.1016/j.biomaterials.2011.12.030

Xu ZQ, Flavin MT, Flavin J (2014) Combating multidrug-resistant Gram-negative bacterial infections. Expert Opin Investig Drugs 23:163-182. https://doi.org/10.1517/13543784.2014.848853

Yang X, Grailer JJ, Pilla S et al (2010) Tumor-targeting, pH-responsive, and stable unimolecular micelles as drug nanocarriers for targeted cancer therapy. Bioconjug Chem 21:496-504. https://doi. org/10.1021/bc900422j

Yount NY, Bayer AS, Xiong YQ, Yeaman MR (2006) Advances in antimicrobial peptide immunobiology. Biopolym - Pept Sci Sec. 84:435-458. https://doi.org/10.1002/bip.20543

Zhang Y, Liu Y, Sun Y et al (2014) In vitro synergistic activities of antimicrobial peptide brevinin-2CE with five kinds of antibiotics against multidrug-resistant clinical isolates. Curr Microbiol 68:685-692. https://doi.org/10.1007/s00284-014-0529-4

Zhao F, Yin H, Zhang Z, Li J (2013a) Folic Acid Modified Cationic $\gamma$-Cyclodextrin-oligoethylenimine Star Polymer with Bioreducible Disulfide Linker for Efficient Targeted Gene Delivery. ACS Publ 14:476-484. https://doi.org/10.1021/bm301718f

Zhao YQ, Wang LP, Ma C et al (2013b) Preparation and characterization of tetrandrine-phospholipid complex loaded lipid nanocapsules as potential oral carriers. Int J Nanomedicine 8:4169-4181. https://doi.org/10.2147/IJN.S50557

Zhou C, Qi X, Li P et al (2010) High potency and broad-spectrum antimicrobial peptides synthesized via ring-opening polymerization of $\alpha$-Aminoacid-N-carboxyanhydrides. Biomacromol 11:60-67. https://doi.org/10.1021/bm900896h

Zu Y, Sun W, Zhao X et al (2014) Preparation and characterization of amorphous amphotericin B nanoparticles for oral administration through liquid antisolvent precipitation. Eur J Pharm Sci 53:109-117. https://doi.org/10.1016/j.ejps.2013.12.005

Publisher's Note Springer Nature remains neutral with regard to jurisdictional claims in published maps and institutional affiliations. 